\title{
DUKE FEL LAB STORAGE RING ARC VACUUM SYSTEM UPGRADE
}

\author{
G. Swift, M. Johnson, V.N. Litvinenko, Free Electron Laser Laboratory, Physics Department, Duke \\ University, Durham, NC, USA
}

\begin{abstract}
The Duke FEL Lab Storage Ring vacuum system has provided reliable UHV operation since commissioning in 1994. Upgrade of the vacuum system is now in progress. Completion of crotch absorber installation will now allow full power operation (1 Amp @ $1 \mathrm{GeV})$. Since high power operation will increase the gas load in the arcs, additional pumping will be required to maintain (and improve) the beam lifetime. To meet this demand we are planning to install TSP modules and bakeout the arc chambers this fall.
\end{abstract}

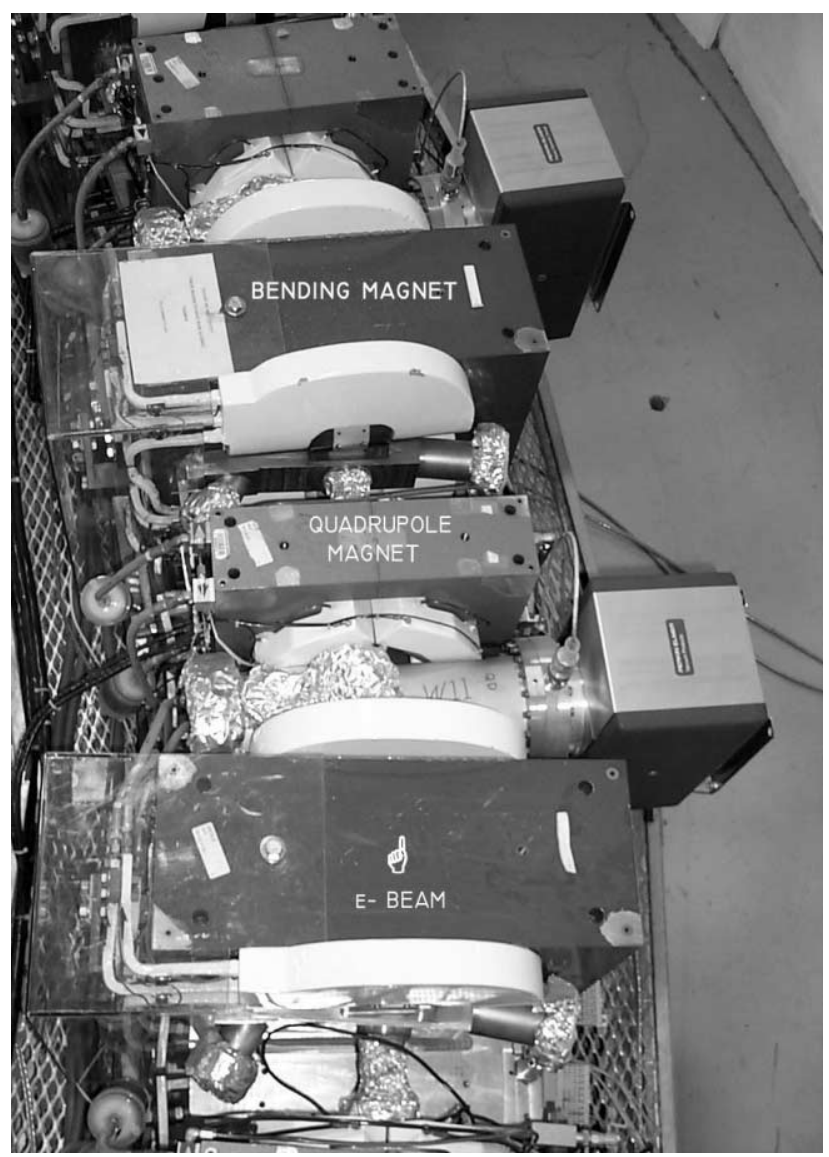

Fig. 1

Storage Ring Arc Section

\section{INTRODUCTION}

The $1 \mathrm{GeV}$ Duke Electron Storage Ring was initially commissioned in November 1994 [1]. The Arc vacuum chambers (18 per arc) were installed with a $60 \mathrm{l} / \mathrm{s}$ ion pump attached to each chamber and without the custom NEG (Non-Evaporative Getter) module, originally specified for distributed pumping. This has been adequate to maintain the Arc vacuum and provide 4 hours lifetime at $1 \mathrm{GeV}$ and $4 \mathrm{~mA}$ of beam current [1]. This year, the installation of new End-of-Arc ("Crotch") vacuum chambers, with water cooled, copper synchrotron radiation absorbers, was completed. Since continual operation at higher power is now possible, additional pumping will be needed to counter the gas load that is expected from the Arc chamber absorbers. We are planning to install a Titanium Sublimation Pump (TSP) module on each Arc chamber as an economical alternative to meet this need. The TSP installation will occur in conjunction with an upcoming shutdown to upgrade and magnetically measure the Arc quadrupole magnets.

The vacuum work will consist of :

- Arc chamber removal from the Ring

- Installation of the TSP module

- Vacuum processing

Leak check

Degas the TSP filaments

Vacuum bakeout of each assembly

- Installation on the Ring

\section{THE ARC VACUUM SYSTEM}

\subsection{Description}

18 arc vacuum chambers connect end-to-end around each arc, see Fig. 1. Each chamber passes through one dipole and one quadrupole magnet, a stripline BPM [2] is located on the downstream beamline flange of the chamber. The inlet flange has a short, RF shielded, welded bellows attached. The water cooled copper absorber runs inside the chamber beside the beam path, it has a copper screen which surrounds the e- beam to provide an internal shape transition for RF smoothing. A $60 \mathrm{l} / \mathrm{s}$ differential ion pump is mounted to the 6" diameter tube (plennum chamber) that sits between the dipole and quadrupole magnets. The NEG module shown in fig. 2 was never installed.

\subsection{History}

The arc chambers were last baked-out during fabrication, in 1987 . Then they were stored, vented with dry $\mathrm{N}_{2}$, for 5 years. The $60 \mathrm{l} / \mathrm{s}$ ion pumps were attached during installation on the Storage Ring.. The chambers were installed on the arcs; then kept under vacuum for about 1-1/2 years before the ring was completed and commissioned in 1994. The nominal, static (w/o e- beam), arc chamber vacuum has been, according to ion gauge readings, $2 \mathrm{E}-10$ torr. During operation, the pressure has 
been in the -9 torr range, dependent on the beam current. Beam lifetime, 3 to 4 hours.

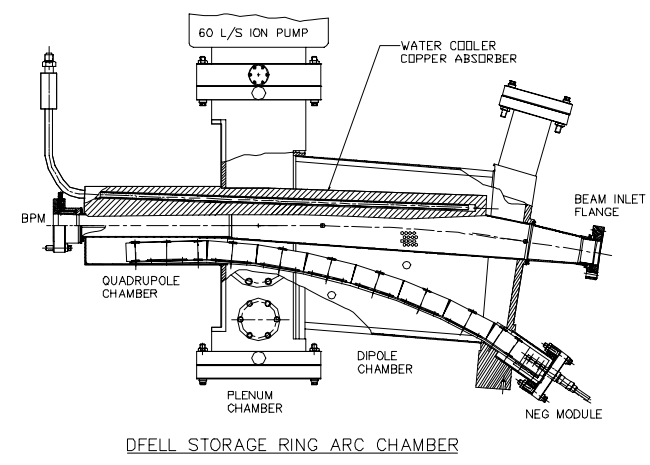

Fig. 2

Nominally, each chamber has:

- Internal surface area $7000 \mathrm{~cm}^{2} 304 \mathrm{SS}$

$1700 \mathrm{~cm}^{2}$ OFHC Copper

- Volume

$$
10,000 \mathrm{~cm}^{3}
$$

\subsection{Arc chamber static outgassing rate}

- $\quad \mathrm{S}$ - pumping speed, liters/sec

- $\quad$ P - pressure, torr

- A - surface area, $\mathrm{cm}^{2}$

Static Outgassing Rate $=\frac{S \times P}{A}$

$=\frac{60 \mathrm{l} / \mathrm{s} \times 2.0 E-10 \text { torr }}{7000+1700 \mathrm{~cm}^{2}}=1.4 E-12 \frac{\mathrm{t}-1}{\mathrm{~s}-\mathrm{cm}^{2}}$

This is consistent with the published outgassing rates for well baked 304 stainless steel [3].

\section{TITANIUM SUBLIMATION PUMP MODULE}
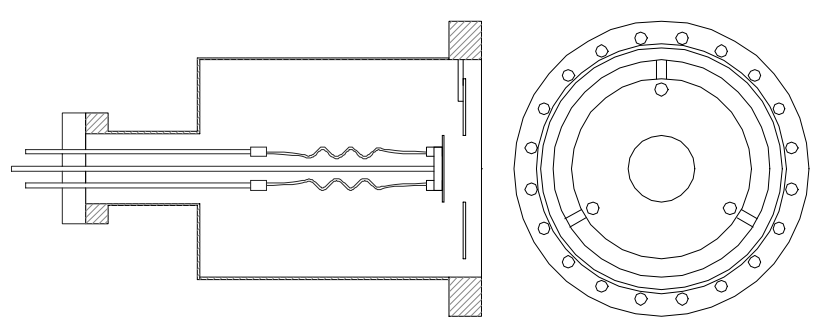

Fig. 3

\subsection{Description of TSP Module}

The TSP pump is a commercially available unit, 4 filaments are connected to high current, electrical feedthroughs on a $3-3 / 8$ " CF type flange. Each filament is made from coiled, $2.1 \mathrm{~mm}$ diameter, $85 \% \mathrm{Ti}$ and $15 \% \mathrm{Mo}$ alloy wire. The TSP pump mounts inside a custom made, 6"diameter, canister with an 8"CF type inlet flange. The vacuum inlet has a simple sputter/heat shield made of 304 stainless steel (Fig. 2). The TSP module assembly will mount onto the 8" CF flange on the arc chamber plenum, opposite the $60 \mathrm{l} / \mathrm{s}$ ion pump (fig. 3).

\subsection{Reasoned TSP Performance}

The TSP module should have over 100 sq' of active Ti sputtered surface area on the interior walls. If the pumping speed per sq" for a Titanium sputtered surface is over $20 \mathrm{l} / \mathrm{s}$ at $20^{\circ} \mathrm{C}$ [4]. Then inside the TSP module, the pumping speed should be over 20001/s. The conductance of the pump inlet flange w/ sputter shield will be a limiting factor. The total aperture at the pump inlet is 11 sq' $\left(71 \mathrm{~cm}^{2}\right)$. Using the engineering formula for conductance, $\mathrm{C}$, of an aperature for air at $20^{\circ} \mathrm{C}[5]$ :

$$
C \mathrm{l} / \mathrm{s}=11.6 \times A \mathrm{~cm}^{2}=11.6 \times 71 \mathrm{~cm}^{2}=8321 / \mathrm{s}
$$

\subsection{TSP Test}

A simple test of the TSP performance was conducted. A 60 1/s ion pump and TSP module were assembled on a spare arc chamber, see Fig. 4. The assembly was pumped down, pinched off and left under vacuum for 3 weeks and reached a steady pressure of $1.2 \mathrm{E}-9$ torr. The TSP was activated for $1 \mathrm{~min} @ 50 \mathrm{amps}$; in 2 days the pressure fell to $2.0 \mathrm{E}-10$ torr.

If the total gas load, $Q$ is unchanged after NEG activation then:

$$
\begin{aligned}
& Q=S_{1} \times P_{1} \text { and } \\
& Q=S_{2} \times P_{2}
\end{aligned}
$$

The NEG module effective pumping speed, $\mathrm{S}_{\mathrm{NEG}}$ is:

$$
\begin{aligned}
\mathrm{S}_{\mathrm{NEG}} & =\mathrm{S}_{2}-\mathrm{S}_{1}=\frac{S_{1} \times P_{1}}{P_{2}}-S_{1} \\
S_{N E G} & =\frac{60 \mathrm{l} / \mathrm{s} \times 1.2 E-9 \mathrm{torr}}{2.0 E-10 \mathrm{torr}}-60=300 \mathrm{l} / \mathrm{s}
\end{aligned}
$$

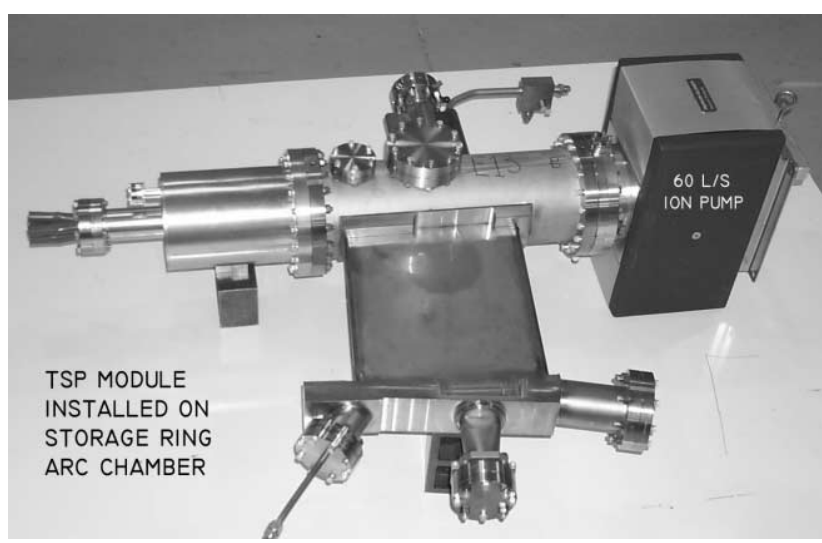

Fig. 4 


\subsection{TSP Installation}

The arc chambers will be removed from the storage ring for TSP installation. Then the assembly will be baked-out at $180^{\circ} \mathrm{C}$ for 72 hours and kept under vacuum until installation on the storage ring arc. Activation will occur after system pump-down to UHV pressure; < $2 \mathrm{E}-9$ torr; 1 filament on each module, around the arc, will be powered at 50 amps for 1 minute, in turn. Experience has shown re-activation may be needed every 3 to 6 months, dependent on e- beam operation.

\subsection{Projected System Performance}

Adding 300 1/s of pumping speed to the Storage Ring Arc Chamber discussed in paragraph 2.2 is expected to lower the static pressure by about 1 decade for a given gas load.

$$
\frac{S_{1} \times P_{1}}{S_{2}}=\frac{601 / \mathrm{s} \times 2.0 E-10 \text { torr }}{3601 / \mathrm{s}}=3.3 E-11 \text { torr }
$$

\section{CONCLUSION}

The augmentation of an ion pumped system with TSP or NEG pumps has become common practice for UHV systems. In 1986, when the ion pumps for this storage ring were specified, compound ion pumps (w/TSP or NEG) were not available as "off the shelf" components. Although a distributed pump may provide better vacuum performance, the lower cost and risk of a simple TSP module is an attractive option to producing the custom NEG module originally specified.

Our goal is to lower the storage ring arc pressure as much as possible, safely and economically. The basic vacuum axiom, $P=\frac{Q}{S}$ indicates, in order to lower to pressure you must, increase the pumping speed $\mathrm{S} \& /$ or decrease the gas load $\mathrm{Q}$. The outgassing rate of the arc chambers is already normal for a UHV system, although a small improvement is expected from the planned bakeout. This TSP module has demonstrated an effective pumping speed sufficient to lower the arc pressure in torr by about 1 decade. It is economical and reliable. The option is still available to add a distributed NEG pump, when funds are available and the cost is justified.

\section{REFERENCES}

[1] V. N. Litvinenko, et. al., "Commissioning of the Duke Storage Ring", Proceedings of 1995 Particle Accelerator Conference, Dallas, TX May 1-5, V. 1,P. 213.

[2] P. Wang, et. al.. "Beam Position Monitors for Duke FEL Storage Ring", Proceedings of 1999 Particle Accelerator Conference, New York, NY.

[3]Santeler, Donald J. "Estimating the gas partial pressure due to diffusive outgassing," J Vac Sci Tech A 10(4) 1992 pp.1879-74.

[4] Varian Vacuum Technologies, Product Catalog 2000, p139.

[5] C.M. Van-Atta, "Vacuum Science and Engineering", (2-94), copyright1965, McGraw Hill Inc., USA, 65-17497 